\title{
DETEKSI DINI MASALAH KESEHATAN REPRODUKSI MELALUI POS KESEHATAN REMAJA
}

\author{
Wilda Rezki Pratiwi', Hamdiyah², Asnuddin ${ }^{3}$ \\ 'STIKES Muhammadiyah Sidrap \\ korespondensi email: wildapratiwi06@gmail.com \\ ${ }^{2}$ STIKES Muhammadiyah Sidrap \\ email: hamdiyahliyaaa@gmail.com \\ ${ }^{3}$ STIKES Muhammadiyah Sidrap \\ email: asnuddin20@gmail.com
}

\begin{abstract}
Marioriawa is one of the sub-districts located in Soppeng Regency with an area of 320 Km2 cover by 5 villages (Bulue, Laringgi, Patampanua, Panincong, Tellulimpoe and 5 villages (AttangSalo, Batu-Batu, Limpomajang, Manorang Salo, Attang Salo) with average population of 27,512 with a density of 86 people $/ \mathrm{km} 2$. In Marioriawa there are 2 high schools (SMAN 01 Soppeng and SMK 02 Soppeng). The students in SMAN 01 Soppeng classified to adolescents in Soppeng Regency precisely in Laringgi village a total of 487 people have not been fully checked out regularly and the discovery of several cases of pregnancy outside marriage, early marriage, HIVIAIDS in rural areas and adolescent health problems (anemia, stunting, KEK and obesity). This is a problem because, lack of adolescent knowledge about health reproduction, identification of new health problems found at the time the teenager will become ca lon mother / father, due to lack of early detection in their teens. It's just that physical growth in adolescents is not always accompanied by the maturity of thinking and emotional abilities. In addition, in adolescence there is also a process of self-introduction, and failure in the process of self-introduction can cause various problems. The method used is the lecture method with health education and adolescent health checks through the establishment of adolescent health posts (PKR) in collaboration with the School Health Unit (UKS) at SMAN 01 Soppeng. The results of the activity are an increase in knowledge after giving material about adolescent health, checking vital signs, HbSAg examination, physical examination of adolescents, HIV testing, and hemoglobin examination. From the results of the examination found that 86 adolescents were found to suffer from mild anemia with hemoglobin levels below $10 \mathrm{gr} / \mathrm{dl}$, as many as 1 person infected with HBsAg, 2 people found a lump in the breast and no HIV patients were found in adolescents. Conclusions are able to detect symptoms / signs early if certain diseases occur in him that are related to the reproductive system, adolescents in rural areas free from sexually transmitted diseases (STDs) and the importance of education to check themselves routinely before they become prospective parents. Suggestion of support from parents to carry out routine health check-up of their children not only to do health check at the time the child / teen complains of pain in certain body part.
\end{abstract}

Keywords: teenagers; health; early detection; reproduction 


\section{ABSTRAK}

Kecamatan Marioriawa merupakan salah satu Kecamatan yang terletak di Kabupaten Soppeng dengan luas wilayah 320 Km2 menaungi 5 Desa (Bulue, Laringgi, Patampanua, Panincong, Tellulimpoe) dan 5 kelurahan (Attang Salo, Batu-Batu, Limpomajang, Manorang Salo, Attang Salo) dengan rata-rata jumlah penduduk 27.512 dengan kepadatan jiwa 86 jiwa/km2. Di Kecamatan Marioriawa memiliki Sekolah Menengah Atas sebanyak 2 (SMAN 01 Soppeng dan SMKN 02 Soppeng). Siswa-siswi SMAN 01 Soppeng yang tergolong remaja di Kabupaten Soppeng tepatnya di desa Laringgi yang berjumlah 487 orang belum sepenuhnya memeriksakan dirinya secara berkala dan ditemukannya beberapa kasus kehamilan diluar nikah, pernikahan dini, HIV/AIDS dipedesaan dan masalah kesehatan remaja (anemia, stunting, KEK dan kegemukan). Hal ini yang menjadi permasalahan karena, kurangnya pengetahuan remaja tentang kesehatan reproduksinya, identifikasi masalah kesehatan baru ditemukan pada saat remaja tersebut akan menjadi calon ibu/ayah, karena kurangnya deteksi dini pada usia remaja. Hanya saja, pertumbuhan fisik pada remaja tidak selalu disertai dengan kematangan kemampuan berpikir dan emosional. Selain itu, di masa remaja juga terjadi proses pengenalan jati diri, dan kegagalan dalam proses pengenalan diri ini bias menimbulkan berbagai masalah. Metode yang digunakan adalah metode ceramah dengan penyuluhan dan pemeriksaan kesehatan remaja melalui pembentukan pos kesehatan remaja (PKR) bekerjasama dengan UKS di SMAN 01 Soppeng. Hasil kegiatan adalah peningkatan pengetahuan setelah pemberian materi tentang kesehatan remaja, melakukan pemeriksaan tanda-tanda vital, pemeriksaan HbSAg, pemeriksaan fisik, pemeriksaan HIV, dan pemeriksaan Haemoglobin. Dari hasil pemeriksaan didapatkan bahwa 86 remaja menderita anemia ringan dengan kadar haemoglobin dibawah $10 \mathrm{gr} / \mathrm{dl}$, sebanyak 1 orang terinveksi HbSAg, 2 orang didapatkan benjolan pada bagian payudara dan tidak ditemukan adanya penderita HIV pada remaja. Kesimpulan mampu mendeteksi lebih awal gejala I tanda jika terjadi penyakit tertentu pada dirinya yang berkaitan dengan system reproduksinya,remaja di pedesaan bebas dari PMS dan pentingnya edukasi untuk memeriksakan dirinya secara rutin sebelum menjadi calon orang tua. Saran adanya dukungan dari orang tua untuk melakukan pemeriksaan kesehatan anaknya secara rutin bukan hanya melakukan pemeriksaan dipelayanan kesehatan pada saat remaja mengeluhkan sakit dibagian tubuh tertentu.

Kata Kunci: remaja; kesehatan: deteksi dini; reproduksi

\section{PENDAHULUAN}

Remaja merupakan masa transisi dari anak-anak menjadi dewasa. Pada periode ini berbagai perubahan terjadi, baik perubahan hormonal, fisik, psikologis maupun sosial (Aisyaroh, 2011). Kesehatan reproduksi adalah sekumpulan metode, teknik, dan pelayanan yang mendukung kesehatan dan kesejahteraan reproduksi melalui pencegahan dan penyelesaian masalah kesehatan reproduksi yang menyangkup kegiatan seksual, status kehidupan dan hubungan perorangan, bukan semata konsultasi dan perawatan yang berkaitan dengan reproduksi dan penyakit yang ditularkan melalui hubungan seks (Indah Dian Permata, 2017).

Program kesehatan reproduksi remaja mulai menjadi perhatian karena beberapa alasan yaitu ancaman HIVIAIDS menyebabkan prilaku seksual dan 
kesehatan reproduksi remaja, kejadian IMS yang tertinggi pada remaja khususnya perempuan, jumlah kelahiran pada remaja dibawah usia 20 tahun pun meningkat karena kurangnya pendidikan seksual atau kesehatan reproduksi serta pelayanan yang dibutuhkan remaja, pengetahuan dan praktik pada tahap remaja akan menjadi dasar perilaku yang sehat pada tahap selanjutnya dalam kehidupan remaja sehingga investasi pada program kesehatan reproduksi remaja akan bermanfaat selama hidupnya (Lala, 2015). Isu-isu yang berkaitan dengan kesehatan reproduksi menjadi isu yang sangat sensitif. Masa remaja sebagai titik awal proses reproduksi menunjukan persiapan strategi interfrensi perlu dimulai jauh sebelum usia subur (Putro, 2017). Nilai anak perempuan dan laki-laki dalam keluarga dan masyarakat, dan bagaimana perlakuan yang mereka terima merupakan faktor penting yang turut menentukan kesehatan reproduksi mereka dimasa yang akan dating (Hariyati, 2015).

Promosi dan pemeriksaan sebagai upaya pencegahan masalah kesehatan reproduksi juga perlu diarahkan pada masa remaja oleh karena itu kesehatan reproduksi remaja perlu ditangani secara khusus dengan cara-cara yang ditunjukan untuk menyiapkan mereka menjadi remaja yang kelak akan menjadi orang tua (Miswanto, 2014). UKS merupakan program yang dilakukan disekolah sebagai upaya media kesehatan siswa. Pos Kesehatan Remaja (PKR) yang digagas menjadi tahap awal terjalinya kerjasama dengan UKS sekolah untuk meningkatkan derajat kesehatan anak bangsa dan mempersiapkan remaja sedini mungkin bagi calon ibu dari aspek kesehatan reproduksinya.

Kecamatan Marioriawa merupakan salah satu kecamatan yang terletak di Kabupaten Soppeng dengan luas wilayah $320 \mathrm{~km}^{2}$ menaungi 5 Desa (Bulue, Laringgi, Patampanua, Panincong , Tellulimpoe) dan 5 Kelurahan (Attang Salo, Batu-Batu, Limpomajang, Manorang Salo, Attang Salo) dengan rata-rata jumlah penduduk 27.512 dengan kepadatan jiwa 86 jiwa/ $/ \mathrm{km}^{2}$. Di Kecamatan Marioriawa terdapat Sekolah Menengah Atas, yaitu SMA Negeri 01 Soppeng dan SMK Negeri 02 Soppeng (Indriyanti, Farida Gaffar, 2019). Masalah Remaja bukan menjadi prioritas utama pemerintah setempat, sehingga isu-isu yang berkaitan dengan kesehatan reproduksi remaja masih sangat minim. Oleh karena itu, diharapkan dengan adanya kegiatan Pos Kesehatan Remaja menjadi tahap awal terjalinnya kerjasama dengan pemerintah setempat untuk meningkatkan derajat kesehatan pada remaja (Marioriawa).

Siswa-siswi SMA Negeri 01 Soppeng yang tergolong remaja di Kabupaten Soppeng tepatnya di desa Laringgi yang berjumlah 487 orang belum sepenuhnya memeriksakan dirinya secara berkala dan ditemukannya beberapa kasus kehamilan diluar nikah, pernikahan dini, HIV/AIDS dipedesaan dan masalah kesehatan remaja (anemia, stunting, kekurangan energy kronik dan kegemukan). Hal ini yang menjadi permasalahan karena, kurangnya pengetahuan remaja tentang kesehatan reproduksinya, identifikasi masalah 
kesehatan baru di temukan pada saat remaja tersebut akan menjadi calon ibu atau ayah , karena kurangnya deteksi dini pada usia remaja.

Berdasarkan masalah yang dialami, maka inilah yang melatar belakangi pengabdi melakukan pengabdian masyarakat tentang pos kesehatan remaja di SMA Negeri 01 Desa Laringgi Kecamatan Marioriawa Kabupaten Soppeng.

\section{METODE PELAKSANAAN}

Metode yang digunakan dalam program ini adalah penyuluhan dengan metode ceramah (Zuraida Usman Bany, Sunnati, 2014). Penyuluhan yang dilakukan tentang kesehatan reproduksi remaja, dampak pernikahan dini, anemia, KEK, Stunting dan kegemukan. Sebelum dilakukan penyuluhan dilakukan pre-test dengan membagikan kuisioner terkait materi penyuluhan dan melakukan post-test setelah penyuluhan yang bertujuan untuk mengetahui peningkatan pengetahuan siswa. Selanjutnya dilakukan pemeriksaan kesehatan kepada siswa-siswi dikelas XI-XII yang berjumlah 256 siswa/siswi. Jenis pemeriksaan yang dilakukan adalah pemeriksaan tanda-tanda vital, pemeriksaan $\mathrm{HbSAg}$, pemeriksaan fisik remaja, pemeriksaan HIV, dan pemeriksaan HB. Pada tahap akhir dilakukan pendampingan pada remaja yang terdeteksi menderita penyakit tertentu dan melakukan pendampingan selama pengobatan. Adapun kegiatan ini dilaksanakan di SMA Negeri 01 Desa Laringgi Kecamatan Marioriawa Kabupaten Soppeng. Dilaksanakan selama 4 (empat) bulan mulai bulan Agustus sampai dengan November 2019.

\section{HASIL DAN PEMBAHASAN}

Program Pos Kesehatan Remaja yang dilaksanakan di SMA Negeri 01 Kabupaten Soppeng dapat dinilai sudah berjalan dengan baik dibuktikan dengan semua kegiatan dapat terlaksana sesuai dengan rencana awal pelaksanaan program. Respon yang di berikan siswa-siswi dalam perkenalan awal sangat baik, mereka sangat mendukung dan antusias mengikuti program ini.

Langkah selanjutnya yang dilakukan adalah melakukan penyuluhan kesehatan yang berguna untuk meningkatkan pengetahuan remaja tentang kesehatan dirinya. Sebelum dilakukan penyuluhan kesehatan, terlebih dahulu melakukan pengisian kuisioner untuk mengetahui pengetahuan remaja SMA tentang kesehatan reproduksi dan didapatkan hasil lebih banyak tidak tahu tentang penyakit, penanganan dan pencegahan kesehatan reproduksi remaja. Dan hasil yang didapatkan setelah penyuluhan terdapat peningkatan pengetahuan tentang kesehatan reproduksi sebesar 95,7\% sebagaimana grafik pada gambar 1 berikut. 


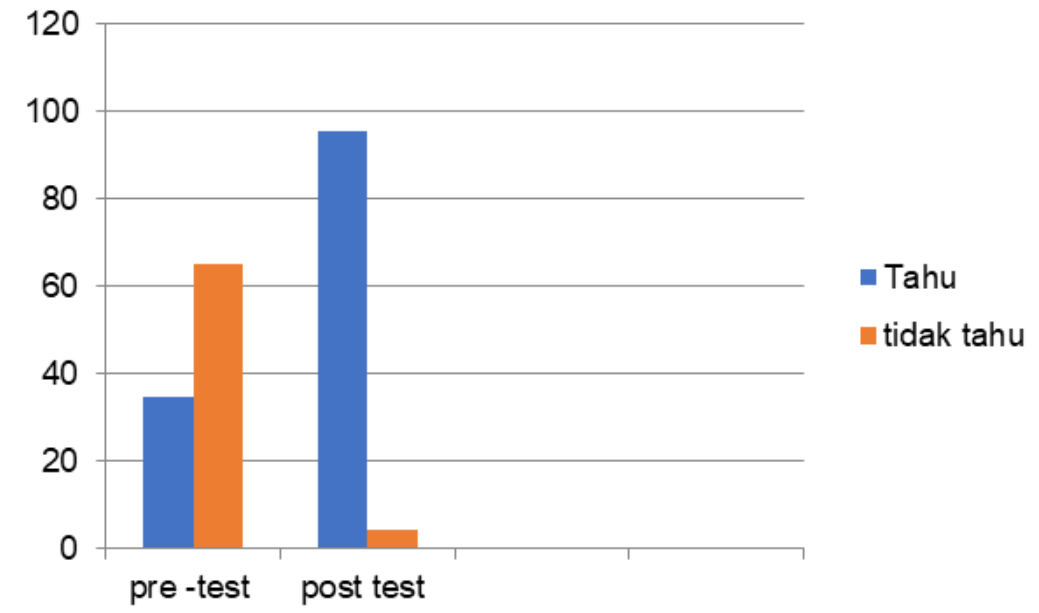

Gambar 1. Pengetahuan pre test dan post test penyuluhan kesehatan

\section{Siswa (Remaja)/org}

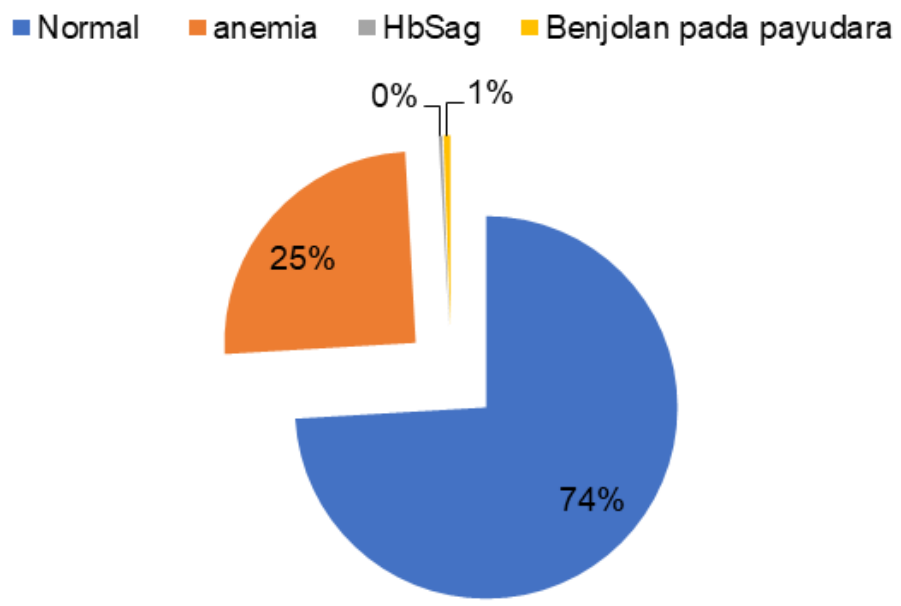

Gambar 2. Hasil pemeriksaan kesehatan siswa

Pada tahap selanjutnya dilakukan pemeriksaan kesehatan kepada siswa-siswi dikelas XI-XII yang berjumlah 256 siswa/siswi. Jenis pemeriksaan yang dilakukan adalah pemeriksaan tanda-tanda vital , pemeriksaan $\mathrm{HbSAg}$, pemeriksaan fisik remaja, pemeriksaan HIV, dan pemeriksaan HB. Dari hasil pemeriksaan didapatkan bahwa 86 remaja didapatkan menderita anemia ringan dengan kadar haemoglobin dibawah $10 \mathrm{gr} / \mathrm{dl}$, sebanyak 1 orang terinveksi HbSAg, 2 orang didapatkan benjolan pada bagian payudara (Gambar 2). 
Pada tahap akhir dilakukan pendampingan pada remaja yang terdeteksi menderita penyakit tertentu dan dilakukan pendampingan selama pengobatan (Martino, Sulistyowati, \& Purnomo, 2018). Bagi remaja yang didapatkan terdiagnosis penyakit diatas, maka langkah selanjutnya yaitu melakukan pertemuan dengan orang tua remaja tersebut dan mejelaskan temuan hasil pemeriksaan yang dilakukan dengan didampingi oleh pihak puskesmas setempat dan kepala sekolah. Untuk remaja yang menderita anemia diberikan terapi obat suplemen tambah darah dengan dosis $1 \times 1$ dan akan dilakukan evaluasi pemeriksaan haemoglobin setiap 1 bulan sekali selama 3 bulan berturut-turut. Bagi yang terdiagnosa penyakit lainya disarankan untuk melakukan pemeriksaan lanjutan di pelayanan kesehatan terlengkap untuk mendapatkan pengobatan dari dokter spesialis.

Penyuluhan kesehatan merupakan kegiatan penambahan pengetahuan yang diperutukkan bagi masyarakat melalui penyebaran pesan. Tujuan kegiatanp enyuluhan kesehatan yaitu untuk mencapai tujuan hidup sehat dengan cara mempengaruhi prilaku masyarakat baik itu secara individu atau pun kelompok dengan menyampaian pesan (Johariyah \& Mariati, 2018).

Dalam hal ini kesehatan reproduksi remaja adalah suatu kondisi sehat yang menyangkut sistem, fungsi dan proses reproduksi yang dimiliki oleh remaja (Hasanah, 2016). Pengertian sehat di sini tidak semata-mata berarti bebas penyakit atau bebas dari kecacatan namun juga sehat secara mental serta social kultural. Perlu diketahui bila remaja menurut UU Perlindungan Anak adalah seseorang yang berusia antara 10-17 tahun, dan merupakan kelompok penduduk Indonesia dengan jumlah yang cukup besar (hampir $20 \%$ dari jumlah penduduk). Remaja merupakan calon pemimpin dan pengerak pembangunan di masa depan.

Karena itu remaja merupakan masa yang sangat berharga bila mereka berada dalam kondisi kesehatan fisik dan psikis, serta pendidikan yang baik. Di dalam masa remaja terjadi apa yang dinamakan growth spurt atau pertumbuhan cepat, juga pubertas. Pada fase tersebut, terjadi pertumbuhan fisik disertai perkembangan mental-kognitif, psikis, juga terjadi proses tumbuh kembang reproduksi yang mengatur fungsi seksualitas (Putro, 2017).

\section{KESIMPULAN}

Peningkatan pengetahuan remaja setelah pemberian materi sebesar 95,7\%, pemeriksaan tanda-tanda vital, pemeriksaan $\mathrm{HbSAg}$, pemeriksaan fisik remaja, pemeriksaan HIV, dan pemeriksaan Haemoglobin. Dari hasil pemeriksaan didapatkan bahwa 86 remaja didapatkan menderita anemia ringan dengan kadar haemoglobin dibawah $10 \mathrm{gr} / \mathrm{dl}$, sebanyak 1 orang terinveksi HbSAg, 2 orang didapatkan benjolan pada bagian payudara dan tidak ditemukan adanya penderita HIV pada remaja.

Luaran dalam pengabdian masyarakat ini adalah menjadikan remaja generasi yang sehat dalam rangka meningkatkan kualitas hidup di masa depan melalui Remaja mampu mendeteksi lebih awal gejala / tanda jika terjadi 
penyakit tertentu pada dirinya yang berkaitan dengan system reproduksinya, b) Remaja di pedesaan bebas dari penyakit menular seksual (PMS), c) Remaja di edukasi untuk memeriksakan dirinya secara rutin sebelum mereka menjadi calon orang tua.

\section{UCAPAN TERIMA KASIH}

Teriring rasa syukur dan bahagia, kami mengucapkan terimakasih kepada semua pihak yang terlibat dan mendukung dalam kegiatan ini, untuk dosen yang terlibatdalam kegiatan ini yang tidak henti-hentinya memberikan saran dan kritikan selama penyusunan, dr. Bambang Roesmono, MM selaku ketua STIKES Muhammadiyah Sidrap, Nurjanna, S.ST., M. Keb selaku ketua Prodi DIII Kebidanan STIKES Muhammadiyah Sidrap yang telah memberikan masukan-masukan berharganya kepada kami. Secara Khusus kami juga mengucapkan terimakasih kepada pihak sekolah SMAN 01 Kabupaten Sidrap dan Puskesmas Batu-Batu.

\section{DAFTAR RUJUKAN}

Aisyaroh, N. (2011). Upaya Preventif Permasalahan Kesehatan Reproduksi Perempuan Lapas. Jurnal Majalah Ilmiah Sultan Agung, 49(125), 1-13. Retrieved from http://jurnal.unissula.ac.id/index.php/majalahilmiahsultanagung/article/v iew/35

Hariyati, I. (2015). Pemahaman Siswa Terhadap Kesehatan Reproduksi Remaja Melalui Layanan Informasi Di Madrasah Tsanawiyah Ma'arif Ketegan Tanggulangin Sidoarjo. Universitas Islam Negeri Sunan Ampel Surabaya. Retrieved from http://digilib.uinsby.ac.id/583/

Hasanah, H. (2016). Pemahaman Kesehatan Reproduksi Bagi Perempuan: Sebuah Strategi Mencegah Berbagai Resiko Masalah Reproduksi Remaja, 11(2), 229-252. https://doi.org/10.21580/sa.v11i2.1456

Indah Dian Permata. (2017). Pengetahuan Tentang Kesehatan Reproduksi Dengan Kecenderungan Perilaku Seksual Pada Peserta Didik Laki-Laki Kelas XI di SMK Negeri 5 Palembang. Universitas Islam Negeri Raden Fatah Palembang. Retrieved from http://eprints.radenfatah.ac.id/1038/1/indah dian permata $\% 2813350063 \% 29 . p d f$

Indriyanti, Farida Gaffar, K. (2019). Analisis Genangan Banjir Sungai Paddangeng Kabupaten Soppeng. Jurnal Teknik Hidro, 12(1), 12-24. https://doi.org/10.26618/th.v12i1.2463

Johariyah, A., \& Mariati, T. (2018). Efektivitas Penyuluhan Kesehatan Reproduksi Remaja Dengan Pemberian Modul Terhadap Perubahan Pengetahuan Remaja. Jurnal Manajemen Kesehatan Yayasan RS.Dr. Soetomo, 4(1), 38-46. https://doi.org/10.29241/jmk.v4i1.100

Lala, H. (2015). Evaluasi Program Kesehatan Reproduksi Remaja "DAKU!" (Dunia Remajaku Seru) di SMU. JPS (Jurnal Pendidikan Sains), 3(2), 
90-97. https://doi.org/http://dx.doi.org/10.17977/jps.v3i2.7657

Martino, Y. A., Sulistyowati, E., \& Purnomo, Y. (2018). Model Pemberdayaan Santri Ponpes Al-Hidayah Batu Malang Sebagai Kader Kesehatan Berbasis Terapi Herbal. Jurnal Inovasi Hasil Pengabdian Masyarakat (JIPEMAS), 1(2), 86-93. https://doi.org/10.33474/jipemas.v1i2.1514

Miswanto. (2014). Pentingnya Pendidikan Kesehatan Reproduksi dan Seksualitas Pada Remaja. Jurnal Studi Pemuda, 3(2), 111-121. https://doi.org/10.22146/studipemudaugm.32027

Putro, K. Z. (2017). Memahami Ciri dan Tugas Perkembangan Masa Remaja. Aplikasia: Jurnal Aplikasi IImu-IImu Agama, 17(1), 25-32. https://doi.org/10.14421/aplikasia.v17i1.1362

Zuraida Usman Bany, Sunnati, W. D. (2014). Perbandingan Efektifitas Penyuluhan Metode Ceramah dan Demonstrasi Terhadap Pengetahuan Kesehatan Gigi dan Mulut Siswa SD. Cakradonya Dental Journal, 6(1), 619-677. Retrieved from

http://www.jurnal.unsyiah.ac.id/CDJ/article/view/10408/8188 